\title{
MENSTRUATION AND HUMAN RIGHTS: CAN WE MOVE BEYOND INSTRUMENTALIZATION, TOKENISM AND REDUCTIONISM?
}

\author{
DR. INGA T. WINKLER*
}

The last ten years have seen enormous developments in making menstruation matter and pushing it into the public eye through a burgeoning global movement of NGOs, civil society and community-based organizations, social entrepreneurs, international organizations, and activists. The media regularly covers menstruation. The documentary "Period. End of Sentence." has won an Oscar. Many countries have adopted national policies on menstruation. ${ }^{1}$ Yet, despite greater openness and awareness, menstrual stigma persists, and it has profound effects on the realization of human rights across all spheres of life.

Consider that people who menstruate are often unfamiliar with bodily processes, in particular before reaching menarche. They have misconceptions and negative or ambivalent feelings about menstruation. This may cause anxiety and stress and impact their ability to learn. ${ }^{2}$

Consider that many menstruators hesitate to seek medical advice, and those who do are often faced with health care providers who are not trained on menstrual cycle-related conditions. The average diagnostic delay for endometriosis, a painful condition where

\footnotetext{
* Associate Professor in International Human Rights Law at the Central European University in Vienna, Austria, former Lecturer at the Institute for the Study of Human Rights at Columbia University, and Director of the Working Group on Menstrual Health and Gender Justice. Dr. Winkler is particularly interested in the intersections of menstruation, human rights, and culture and focuses on questions of inequalities, marginalization, and representation. As the former Legal Adviser to the UN Special Rapporteur on the human rights to water and sanitation, she continues to bridge academia, policy, and practice and engages with policy-makers on menstrual health.

${ }^{1}$ E.g., Republic of Kenya Ministry of Health, Menstrual Hygiene Management Policy, https://www.health.go.ke/wp-content/uploads/2020/05/MHM-Policy-11-May-2020.pdf [https://perma.cc/JTH3-2A94].

${ }^{2}$ Venkatraman Chandra-Mouli \& Sheila Vipul Patel, Mapping the Knowledge and Understanding of Menarche, Menstrual Hygiene and Menstrual Health Among Adolescent Girls in Low- and MiddleIncome Countries, in Palgrave Handbook of Critical Menstruation Studies 609, 629 (C. Bobel et al. eds., 2020).
} 
uterine tissue grows outside of the uterus, is 7.5 years or more. ${ }^{3}$ Testimonials of gaslighting, dismissal of menstrual pain, and odysseys through the medical system abound.

Consider that menstruators are often labelled and perceived as hysterical, not trustworthy, and unfit for decision-making. ${ }^{4}$ They also experience menstrual pain and cramps that are dismissed as they are told to 'power through.' These stereotypes and lack of accommodations contribute to barriers women experience at the workplace and in public life, resulting in lower earnings, less responsibility, and fewer promotions.

But there is an opportunity to change all of this. With the current momentum around menstruation, it is increasingly framed as a human rights issue. We see such language in $\mathrm{UN}$ documents and many organizations adopt the framing of human rights. ${ }^{5}$ Scholars have argued that "framing the issue as being about the right to safe, healthy and dignified menstruation moves it from being a negative problem to be solved" to "an affirmative principle through which the facts of women and girls' lives are acknowledged and validated."

This paper seeks to briefly unpack what it means to approach menstruation through the lens of human rights. First, I will discuss the predominant way in which human rights framing is presently used and how it is at risk of instrumentalization, tokenism, and reductionism. However, I will also provide a more optimistic view and discuss what the human rights framework has to offer, building on grassroots perspectives as well as normative arguments.

\footnotetext{
${ }^{3}$ Heather C. Guidone, The Womb Wanders Not: Enhancing Endometriosis Education in a Culture of Menstrual Misinformation, in The Palgrave Handbook of Critical Menstruation Studies, supra note 2 , at $269,276$.

${ }^{4}$ Tomi-Ann Robert et al., 'Feminine Protection': The Effects of Menstruation on Attitudes Towards Women, 26 PSYCHOL. WOMEN Q. 131, 131 (2002).

${ }^{5}$ Global Menstrual Health and Hygiene Collective, Statement on the Occasion of the 64th Session of Commission on the Status of Women, WATERAID (Mar. 14, 2019), https://washmatters.wateraid.org/sites/g/files/jkxoof256/files/global-menstrual-health-and-hygienecollectives-statement-for-the-commission-on-the-status-of-women.pdf [https://perma.cc/WL79-PBER].

${ }^{6}$ Jennifer Thomson et al., What's Missing in MHM? Moving beyond Hygiene in Menstrual Hygiene Management, 27 Sexual \& Reprod. Health Matters 12, 14 (2019).
} 


\section{Current Framing: Risks of Instrumentalization, Tokenism, and Reductionism}

Many current efforts to address menstruation through the framing of human rights are at risk of instrumentalization, tokenism, and reductionism. Global organizations in particular tend to instrumentalize human rights to advance narrow, technical fixes in the form of menstrual products and hygiene interventions. At the national level, menstrual product provision is the most common policy. "We like things tangible" is how one Indian interviewee put it. ${ }^{7}$ The water, sanitation, and hygiene (WASH) sector has proven to be an excellent entry point for addressing menstruation. Water and sanitation professionals who deal with feces and sludge management do not seem to be intimidated by a few ounces of blood, mucus, and uterine tissue. Yet, with the focus on water and sanitation comes a priority for facilities and products. These are perceived as quick material fixes to address menstrual needs. I do not want to dismiss the need for something to catch the flow, but the barriers many people face are far more complex and cannot be overcome by a piece of cotton or even medical-grade silicone in menstrual cups alone. What remains under-addressed are the impacts of menstrual stigma on education, work, health, and other human rights.

The use of human rights framing also tends to be tokenistic. Documents and organizations use the frame of dignity, but focus narrowly on ensuring privacy and cleanliness, eschewing a more fundamental understanding of dignity as agency and autonomy. The kits with essentials distributed in humanitarian emergencies are called 'dignity kits.' They include underwear, soap, and menstrual pads — presented as ensuring dignity. This theme also carries through the broader discourse at the UN, which is about "dignity through management," advancing the idea of body management rather than body autonomy. ${ }^{8}$ Beyond enabling people who menstruate to manage, this also creates expectations and responsibilities. People who menstruate are expected to manage, to keep clean, to exercise proper hygiene. As menstruators, we receive the message to keep our messy, leaky bodies under control. Again, these efforts do nothing to address menstrual

\footnotetext{
${ }^{7}$ Nay Alhelou et al., "We Like Things Tangible:" A Critical Analysis of Menstrual Hygiene and Health Policy-Making in India, Kenya, Senegal and the United States pg. 14 (June 20, 2021) (unpublished manuscript) (on file with the Columbia Journal of Gender and Law).

${ }^{8}$ Karen Zivi, Hiding in Public or Going with the Flow: Human Rights, Human Dignity, and the Movement for Menstrual Equity, 42 Hum. RTs. Q. 119 (2020); Chris Bobel \& Breanne Fahs, From Bloodless Respectability to Radical Menstrual Embodiment: Shifting Menstrual Politics from Private to Public, 45 Signs: J. Women Culture \& Soc'y 955 (2020); Chris Bobel, The Managed Body: Developing Girls and Menstrual Health in the Global South (2019).
} 
stigma. Instead, they risk reinforcing it because they do not challenge the notion that menstruation has to be kept hidden. ${ }^{9}$

Finally, the discourse around menstruation and human rights is reductionist. The predominant focus is on the rights to water and sanitation, and when other rights are discussed, it is in a reductionist way. Some texts address the socio-cultural dimension of menstruation, but consistently present culture as restriction and barrier to the realization of human rights rather than also discussing cultural rights in a positive way. Chris Bobel and I conducted an analysis of more than eighty articles in the popular media that deal with cultural and religious menstrual practices and beliefs. We found that menstrual practices were characterized in exaggerated ways, drawing attention to their 'absurdity.' Above all, practices and beliefs are labeled as bizarre and backward. ${ }^{10}$ Such charged language presents menstruating girls and women as victims of their culture, left powerless and oppressed. Not once do the articles in our sample take a positive view of culture and religion and discuss the agency of women and girls in engaging with it. The suggested answer to the question 'what is to be done?' comes down to the abolition of culture. Only then, goes the logic, can girls and women disadvantaged by menstrual beliefs and restrictions achieve gender equality. And since the Global North is presented as having 'overcome' its cultural ties, a linear progression of development away from the backwardness of culture implies that other menstruators should do the same.

Overall, what is lacking in such tokenistic and reductionist use of human rights is the idea of agency and autonomy, and the acknowledgement that agency can take many forms.

\section{Human Rights at a Crossroads}

To anyone who has been engaging with critiques of human rights, none of this will sound surprising. The instrumentalization of human rights and tokenistic and reductionist approaches are all too common. The frames employed in the context of menstruation mirror tactics criticized in other contexts such as Female Genital Cutting and the wearing of the hijab: the representation of culture as oppressive and the "embrace of neoliberal markets" as the perceived remedy. ${ }^{11}$ Scholars from a range of perspectives are

\footnotetext{
${ }^{9}$ BoBel, supra note 8, at 217.

${ }^{10}$ Inga Winkler \& Chris Bobel, "Bizarre" and "Backward": Saviorism and Modernity in Representations of Menstrual Beliefs and Practices in the Popular Media, 33 Feminist Formations (Issue 2) 313 (2021).

${ }^{11}$ See generally Ratna Kapur, Gender, Alterity and Human Rights: Freedom in a Fishbowl 7 (2018); Lila Abu-Lughod, Against Universals: The Dialects of (Women's) Human Rights and Human Capabilities, in
} 
increasingly critical of the human rights 'enterprise,' and some authors call into question the legitimacy of human rights and their operationalization through a focus on liberal freedom.

References to 'twilight' and 'endtimes' suggest that human rights have reached their apex. ${ }^{12}$ However, rather than the end of the road, I argue that human rights have reached a crossroads. We may be witnessing the emergence of a stronger, less institutionalized human rights movement. When examining the critiques in more detail, we see that they largely concentrate their criticism on institutionalized (capitalized) 'Human Rights ${ }^{13}$ and large, global organizations and fail to engage with the ecosystem of grassroots movements, largely in the Global South. ${ }^{14}$ They also center civil and political rights and liberal understandings of freedom ${ }^{15}$ rather than socio-economic rights and distributive justice.

Despite the failures of the human rights movement, human rights remain something that we "cannot not want." 16 Therefore, many authors suggest that human rights can be re-envisioned to address gender injustices. ${ }^{17}$ Such re-envisioning should take place from below, and by connecting the local and the global.

\section{Re-envisioning Human Rights in the Menstrual Movement}

Since the menstrual movement is rather recent, it provides an opportunity. We need to rethink and re-envisage how we do human rights. While I have focused on many

Rethinking the Human 69 (Michelle Molina et al. eds., 2010); Chandra Talpade Mohanty, Under Western Eyes: Feminist Scholarship and Colonial Discourses, 12 BOUNDARY 2333 (1984).

12 See generally Stephen Hopgood, The Endtimes of Human Rights (2013); Eric Posner, The Twilight of Human Rights (2018); SAmuel Moyn, Not Enough: Human Rights in An Unequal World (2018).

${ }^{13} C f$. HopgOOD, supra note 12.

${ }^{14} C f$. Moyn, supra note 12.

${ }^{15} \mathrm{Cf}$. KAPUR, supra note 11.

${ }^{16} I d$.

${ }^{17}$ See generally Bonaventura De Sousa Santos, Toward a New Legal Common Sense: Law, Globalization, and Emancipation (2002); Serene Khader, DeColonizing Universalism: a Translational Feminist Ethic (2018); RAJAgOpal Balakrishnan, InTERNATIONAL LAW FROM Below: Development, Social Movements, and Third World Resistance (2003); César Rodríguez-Garavito, The Future of Human Rights: From Gatekeeping to Symbiosis, 11 SUR InT'L J. HUM. RTS. 499 (2014). 
global developments, discourses, and representations thus far, the menstrual movement is not monolithic. Coalitions such as the Global South Coalition for Dignified Menstruation have adopted a more comprehensive and nuanced understanding of human rights. The Coalition uses the notion of dignity in a broader sense, one that reaches beyond dignity through management. The Coalition calls for "[r]edefin[ing] the narrative on menstruation, from charity to human rights, hygiene to dignity . . ., transform[ing] patriarchal unequal power dynamics and realities, ... turn[ing] media stereotypes on their head [by] counter[ing] the oft reported images of helpless, weak, abused menstruators ... [and] recogniz[ing] and fight[ing] menstrual discrimination and indignity as symptomatic of a widely tolerated, silent pandemic of gender-based violence and inequality . ..."18

This perspective recognizes that menstrual stigma is at the root of any menstrual injustices. ${ }^{19}$ At a fundamental level, menstrual stigma reflects unequal power. ${ }^{20}$ Power can be about the ability to define standards of what is 'normal' and 'acceptable.' Stigma is often a rationale for discrimination. It provides a 'justification,' so that discrimination is seen as natural, necessary, and desirable. It is an element of the structural and social dynamics which (re)produce unequal power relations that impact the realization of many human rights.

The recognition that we must broaden the human rights framing has found reflection in some global human rights statements. For instance, a group of UN independent experts recognized on the occasion of International Women's Day 2019 that "the stigma and shame generated by stereotypes around menstruation have severe impacts on all aspects of ... human rights, including [the] human rights to equality, health, housing, water, sanitation, education, work, freedom of religion or belief, safe and healthy working conditions, and to take part in cultural life and public life without discrimination." ${ }^{21} \mathrm{We}$ need to consider all relevant human rights and address menstrual stigma and its impacts

\footnotetext{
${ }^{18}$ Declaration and Call for Action for Redefining the Menstrual Movement with Dignity at the Centre, Global South Coalition for Dignified Menstruation (Oct. 12, 2020), https://dignifiedmenstruation.org/wp-content/uploads/2020/12/Declaration-_10.12.2020.pdf [https://perma.cc/HMH9-W44T].

${ }^{19}$ Ingrid Johnston-Robledo \& Joan Chrisler, The Menstrual Mark: Menstruation as Social Stigma, 68 SEX ROLES 9 (2013).

${ }^{20}$ Bruce G. Link \& Jo Phelan, Stigma Power, 103 Soc. ScI. \& MED. 24 (2014).

${ }^{21}$ International Women's Day-8 March 2019 Women's Menstrual Health Should No Longer Be a Taboo, United NATions Hum. Rights OfF. OF THE High COMM'R (Mar. 5, 2019), https://www.ohchr.org/EN/NewsEvents/Pages/DisplayNews.aspx?NewsID=24258\&LangID=E [https://perma.cc/4JZE-7LBU].
} 
as rooted in power relations. The human rights principles of (1) non-discrimination and substantive equality, (2) participation, voice and agency, and (3) accountability provide a framework for comprehensive (rather than instrumentalized and tokenistic) and transformative (rather than reductionist) change.

Applying a human rights lens means that we need to look at menstrual stigma and gender injustice and their intersections with other forms of discrimination and marginalization. This is based in provisions on non-discrimination and prohibited grounds of discrimination that have been expanded over the last decades recognizing implicit prohibited grounds. ${ }^{22}$ This prompts us to ask some difficult questions about the current focus of efforts addressing menstruation: by focusing programming on girls in schools (as is currently largely the case), do we further entrench the marginalization of girls who are out of school? By framing menstrual health as an 'adolescent girls"' issue, do we ignore other health issues across the life course, in particular peri-menopause and menopause? Do we acknowledge women who do not menstruate? Conversely, do we address the needs and experiences of menstruators who identify as trans, non-binary, and gender non-conforming? Do we address the unique needs of menstruators with disabilities, who are sometimes forcibly sterilized as a means to 'manage' menstruation? Do we understand how menstrual stigma intersects with race, ethnicity, class, caste, culture, religion, and other factors? And do we recognize the lived experiences of menstruators living in poverty, in detention, on the move, in camps, in shelters, and/or on the streets? At present, we too often ignore these questions. In the menstrual movement, we need a concerted effort in policy, practice, and research to decenter our menstrual health efforts to include all people who menstruate and address the double stigma that many face.

The second key human rights principle is participation, which requires that menstruators are the ones who decide on any aspect related to menstruation. It is about enabling menstruating individuals to deal with menstruation the way they want to. This means not only deciding on which materials to use, but also making decisions about what to do or not do during menstruation, including which social and cultural activities to engage in or not. ${ }^{23}$ It means taking informed decisions about one's body, which demonstrates the importance of menstrual education. ${ }^{24}$ Such education is about

\footnotetext{
${ }^{22}$ U.N. Econ. \& Soc. Council, Comm. on Econ., Soc. and Cultural Rts., General Comment No. 20, U.N. Doc. E/C.12/GC/20 (July 2, 2009).

${ }^{23}$ Trisha Maharaj \& Inga T. Winkler, 'You Don't just Do It because Someone Else Said so': Menstrual Practices and Women's Agency in the Hindu Diaspora of Trinidad, 2021 Culture, Health \& SeXuality 1.

${ }^{24}$ BoBel, supra note 8, at 294.
} 
understanding bodily processes and changes over the life course; it overlaps with comprehensive sexuality education and sexual awareness; it opens up discussions about social norms, gendered expectations, and gender identity; and it provides space for dialogues about cultural and religious meanings of menstruation and their varied interpretations. Participation in human rights terms is about autonomy (including bodily autonomy), voice and agency. ${ }^{25}$

Finally, human rights are fundamentally about accountability, about the roles, responsibilities and relationships between individuals and the state they live in. Individuals can claim their rights and demand accountability, and states have a range of corresponding obligations to make human rights a reality. We often hear that menstrual health is deeply personal, that it depends on individual behavior, habits, and actions. That is certainly true. Yet, this does not make menstrual health any less of a human right (as part of the right to the highest attainable standard of health).

There are a range of obligations states must meet to make this right a reality. Governments must ensure that they do not disadvantage menstruating individuals at a structural level, e.g. through taxes on menstrual products. Barack Obama stated in an interview: "I have no idea why states would tax these as luxury items. . . I suspect it's because men were making the laws when those taxes were passed." ${ }^{26}$ This points to the need to repeal such taxes. It also points to the need to ensure representation in democratic systems - because even with greater awareness, we often see resistance among men as policy-makers and legislators to make menstruation a priority (while it is true that others have acted as champions). Most importantly, governments must create an enabling environment for everyone's menstrual health. This requires promoting menstrual literacy, promoting workplaces that are period-friendly, and tackling gender stereotypes and menstrual stigma. These are the most indirect and least visible obligations but likely the most important ones in realizing human rights.

Overall, approaching menstruation through the lens of human rights continues to have significant potential — provided that we go beyond the narrow and reductionist framing and instead look at human rights in a comprehensive way, as a transformative framework.

\footnotetext{
${ }^{25} \mathrm{Id}$.

${ }^{26}$ Maya Rhodan, President Obama Doesn't Understand the 'Tampon Tax' Either, Time (Jan. 15, 2016) https://time.com/4183108/obama-tampon-tax-sanitary/ [https://perma.cc/XJ9L-RWEW].
} 